\title{
PERAN SELF-AWARENESS DAN EGO SUPPORT TERHADAP KEPUASAN HIDUP REMAJA TIONGHOA
}

\author{
Agoes Dariyo ${ }^{1}$ \\ Fakultas Psikologi Universitas Tarumanagara Jakarta \\ agoesd@fpsi.untar.ac.id
}

\begin{abstract}
.
The objective of this study was to investigate the impact of the self-awareness and ego support on the life satisfaction of adolescence. Participants were 223 subjects (19-21 years). Collecting data by using questionnaires such as: selfawareness, ego support, and the life satisfaction of adolescence. Data was analyzed with multiple regression via SPSS 16.0 software program. Found was the impact of self-awareness on life satisfaction $\left(r^{2}=.052, t=3.467, p=.001\right.$ $<.01)$, the impact of ego support on life satisfaction $\left(r^{2}=0,219, t=7.877, p=\right.$ $0,000<0,01)$, and the impact of self-awareness and ego support on the life satisfaction of adolescence $\left(r^{2}=0, .243, F=35.307, p=0, .000<0,01\right)$.
\end{abstract}

Keywords: : self-awareness, ego support, life satisfaction, adolescence.

\begin{abstract}
Abstrak.
Penelitian ini bertujuan untuk mengetahui pengaruh self-awareness terhadap kepuasan hidup, pengaruh ego support terhadap kepuasan hidup dan pengaruh Self-awareness dan Ego Support terhadap kepuasan hidup remaja, Sebanyak 223 orang remaja (19-21 tahun) terlibat dalam penelitian ini. Teknik pengambilan data dengan menggunakan kuosioner yaitu self-awareness, ego support dan kepuasan hidup. Analisis data dengan menggunakan teknik regresi dan diketahui ada pengaruh Self-awareness terhadap kepuasan hidup $\left(\mathrm{r}^{2}=0, .052, \mathrm{t}=, 3.467, \mathrm{p}=\right.$ $0,001<0,01)$; ada pengaruh ego support terhadap kepuasan hidup $\left(\mathrm{r}^{2}=0,219, \mathrm{t}\right.$ $=7.877, \mathrm{p}=0,000<0,01)$, dan ada pengaruh Self-awareness dan Ego Support terhadap kepuasan hidup $\left(\mathrm{r}^{2}=0, .243, \mathrm{~F}=35.307, \mathrm{p}=0, .000<0,01\right)$. Selanjutnya berbagai penemuan tersebut didiskusikan dalam artikel ini.
\end{abstract}

Kata-kata kunci: self-awareness, ego support, kepuasan hidup dan remaja.

\footnotetext{
1 Agoes Dariyo: Dosen Tetap Fakultas Psikologi Universitas Tarumanagara (Untar) Jakarta. Korespondensi terkait riset ini dengan alamat email: agoesd@fpsi.untar.ac.id. Penelitian ini didanai oleh Lembaga Penelitian dan Publikasi IImiah (LPPI) Untar.
} 


\section{PENDAHULUAN}

Sepanjang sejarah manusia, kepuasan hidup merupakan tujuan penting yang dikejar oleh setiap individu. Kepuasan hidup dipandang sebagai bentuk memenuhi kebutuhan hidupnya. Diener (dalam Eid \& Lassen, 2008) menyatakan kepuasan hidup (life satisfaction) sebagai tujuan penting bagi setiap individu. Kepuasan hidup adalah hasil evaluasi dan penilaian terhadap kehidupan pribadinya (Diener, Oishi \& Lucas, 2015). Setiap orang berupaya keras melakukan hal-hal yang penting dan dianggap perlu untuk mencapai kepuasan hidupnya.

Kepuasan hidup bersifat subjektif artinya masing-masing individu memiliki penghayatan dan penilaian yang berbeda-beda terhadap kepuasan dalam hidupnya. Karena masing-masing individu memiliki perbedaan kepribadian (Adebayo, S. O \& Arogundade, 2011). Ada beberapa pandangan kepuasan hidup disamakan dengan wellbeing (Schimmack, 2009) subjective well-being (kesejahteraan subjektif), atau happiness (kebahagiaan) (Comptom, 2005). Sebagian ahli menyukai kepuasan hidup sebagai evaluasi secara global terhadap seluruh hidupnya (Diener, 2005), namun ada yang menyukai kepuasan hidup sebagai pemenuhan aspek-aspek kehidupan (domains) (Schimack,at al, dalam Eid \& Lassen, 2008).

$$
\text { Remaja memandang }
$$
kepuasan hidup terkait erat dengan bagaimana mereka mampu memenuhi seluruh aspek hidupnya. Diponegoro (2004) menemukan bahwa kepuasan hidup remaja dipengaruhi oleh kehidupan keluarga, pertemanan, sekolah, lingkungan dan dirisendiri. Hanya saja, dalam hal ini, Diponegoro tidak memerinci masing-masing aspek tersebut. Namun demikian, Schimmack et al (dalam Eid \& Lassen, 2008) 
menyatakan keluarga terutama orangtua memberi peran penting bagi kehidupan remaja. Sebab orangtua adalah sebagai role model bagi anak-anak remaja dalam keluarga. Hal ini mengindikan sesuai dengan hasil penelitian Goetzmann, Scholz, Dux, Roellin, Boehler, Muellhaupt, Noll, Wüthrich, and Klaghofer (2012) yang menemukan bahwa kualitas hubungan antar individu satu dengan lainnya memberi pengaruh kepuasan hidup seseorang.

Penelitian Kasimatis \& Guastello (2012) membuktikan bahwa pengasuhan otoritatif mampu memberikan pengaruh bagi remaja unuk memperoleh (mencapai) kepuasan hidup. Dalam hal ini, orangtua harus menunjukkan keteladanan di mata anak-anaknya yang sudah menginjak remaja. Orangtua yang mampu mendidik atau membina anak-anak remaja harus memperlihatkan keharmonisan sebagai orangtua. Masriah, Putri,
\& Radiaswati (2012) menemukan orangtua yang utuh, harmonis dan tidak bercerai menyumbangkan kebahagiaan atau kepuasan hidup bagi remaja. Sebaliknya, orangtua bercerai akan mendorong muculnya ketidakpuasan dalam hidup remaja.

Demikian pula, kepuasan hidup terkait erat dengan pertemanan atau persahabatan yang dikembangkan oleh remaja (Dariyo, 2015). Persahabatan sebagai sarana bagi remaja untuk mengembangkan ketrampilan sosial (social skill) yang berguna dalam upaya menyesuaikan diri dalam lingkungan sosialmasyarakat (Aboud, Mendelson \& Purdy, 2003). Persahabatan berfungsi sebagai sumber dukungan emosional bagi remaja. Remaja memperoleh perhatian dan kesempatan untuk belajar halhal yang positif dari lingkungan pertemanan (Cillessen, Jiang, West \& Laszkowski, . 2005). Dengan demikian, dapat dikatakan bahwa peran oraangtua 
maupun pertemanan memberikan dukungan emosional (ego support) (Kail \& Cavanaugh, 2010) terhadap remaja dalam upaya mencapai kepuasan hidup (Comptom, 2005).

Kepuasan

merupakan penilaian dan penghayatan individual terhadap seluruh aspek kehidupannya. Penilaian ini merupakan hasil dari kesadaran diri (self-awareness) (Brill, 2000; Duval \& Silvia, 2002). Kesadaran diri tumbuhkembang melalui proses dari kematangan konsep diri yaitu suatu kemampuan untuk memandang terhadap keseluruhan aspek-aspek dalam diri individu (Boyd \& Bee, 2012: Rice \& Dolgin, 2008). Goleman (1999) menyatakan bahwa selfawareness merupakan kesadaran diri seseorang yang mampu memahami, menerima dan mengelola seluruh potensi untuk pengembangan hidup di masa depan.
Kesadaran diri yang positif mendorong seseorang untuk mampu menerima kenyataan hidup (self-acceptance) (Brill, 2000), sebab ia dapat mengenali seluruh potensi kekuatan maupun kelemahan dalam dirinya (Thomasson, 2006). Kemampuan untuk menerima seluruh aspek kehidupan akan mendorong munculnya perasaan bermakna (Fridayanti. 2013) dan merasa puas terhadap kehidupannya (Kreuse, 2007, dalam Heintzelman \& King, 2014). Kesadaran diri membuat seseorang dapat menghargai dirisendiri (self-esteem). Dengan demikian, dapat dikatakan bahwa kesadaran diri (self-awareness) memberi pengaruh terhadap kepuasan hidup dalam diri seseorang.

\section{Self-awareness}

Self-awareness ialah

kesadaran diri seseorang yang mampu memahami, menerima dan mengelola seluruh potensi untuk pengembangan hidup di 
masa depan (Goleman (1999). Ada ahli yang menyamakan selfawareness dengan selfconsciousness (Auzoult and Hardy-Massard, 2014). Pada prinsipnya, kesadaran diri terkait erat dengan pemahaman dan penerimaan diri. Dengan kesadaran diri, seseorang berupaya untuk mengetahui seluruh aspek hidup yang berhubungan dengan kelebihan maupun kekurangan dalam dirinya (Thomasson, 2006). Orang yang memiliki kesadaran diri, adalah orang yang menilai dirisendiri terkait dengan pengalaman-pengalaman dalam hidupnya (Andrén, 2012).

Bagi seorang individu, kesadaran diri berfungsi untuk mengendalikan seluruh emosi agar dapat dimanfaatkan dalam menjalin relasi sosial dengan orang lain (Auzoult and HardyMassard, 2014). Ia harus mampu mengendalikan diri dari sifat-sifat emosi negatif, dan lebih menonjolkan hal-hal yang positif, sehingga tidak menganggu hubungan sosial dengan orang lain. Selain itu, kesadaran diri juga berfungsi untuk mengendalikan diri dalam upaya memenuhi kebutuhan hidupnya, agar ia berhasil mengatasi masalah (coping skill) (Duval \& Silvia, 2002).

\section{Ego Support}

Ego support ialah dukungan emosional yang berasal dari lingkungan sosial baik keluarga terutama orangtua, saudara kandung, sanak keluarga maupun teman-teman sebaya (peer group). Dukungan emosional memberikan pengaruh positif terhadap diri seseorang, karena ia merasa diterima oleh lingkungan social (Brill, 2000). Penerimaan sosial merupakan hal terpenting bagi seseorang, karena ia menjadi bagian penting bagi lingkungan sosial. Ia akan belajar dari lingkungan social untuk mengembangkan segenap potensinya demi mencapai tujuan hidupnya yang lebih baik. 
Dukungan emosional akan membuat diri seseorang merasa berharga. Seseorang menyadari bahwa ternyata masih ada perhatian dari lingkungan sosial yang sangat berharga dalam hidupnya Ketika seseorang sedang menghadapi persoalan hidup (life problem), maka dukungan emosional akan menumbuhkan harapan, optimism dan keyakinan diri untuk mengatasi masalah tersebut. Dengan dukungan emosional maka seseoraing merasa yakin untuk dapat menyesuaikan diri dalam lingkungan sosial (Kumalasari \& Ahyani, 2012).

\section{Kepuasan Hidup}

Kepuasan hidup ialah bagaimana seseorang mengevaluasi, menghayati dan merasakan terhadap pemenuhan seluruh aspek kebutuhan dalam hidupnya (Diener, Oishi \& Lucas.2015). Kepuasan hidup bersifat subjektif, artinya masingmasing individu memiliki penghayatan dan penilaian yang berbeda-beda terhadap seluruh aspek hidupnya. Masing-masing individu tidak bisa disamaratakan. Mungkin seseorang merasakan kepuasan hidup ketika ia telah memenuhi standar kebutuhan tertentu; namun hal itu belum tentu akan memuaskan bagi individu yang lain.

Namun demikian, ada beberapa aspek dasar yang menjadi standar kepuasan hidup. Schimack, Diener, Oishi \& Shush (2006, dalam Eid \& Larsen, 2008) menyebutkan 6 dimensi kepuasan hidup pada kelompok kaum muda (remaja) di antaranya: romantic, finances, grades, social life, recreation, dan housing. Romantic ialah hubungan asmara antara individu remaja dengan lawan jenisnya. Finances yaitu ketersediaan dukungan finansial (keuangan) untuk menopang seluruh aktivitas hidupnya. Grades ialah bagaimana pencapaian prestasi akademik yang telah dilakukan oleh seorang 
remaja selama belajar di lingkungan pendidikan formal.

Selain itu, social life ialah kehidupan pertemanan yang dikembangkan oleh seorang remaja bersama dengan temanteman sebayanya. Recreation ialah kehidupan remaja untuk mengisi waktu luang dengan berwisata yang memberi pengaruh positif bagi hidupnya. Housing ialah seluruh aktivitas yang melibatkan anggota-anggota keluarga di rumahnya. Ke-6 dimensi tersebut mencerminkan kebutuhan penting yang sesuai dengan tahap perkembangan bagi remaja. Mereka yang berhasil dalam mencapai kepuasan hidup, maka mereka akan mampu mengembangkan mental yang sehat (mental health) (Lyons, Otis, Huebner, and Hills, 2014).

\section{Penelitian saat ini}

Penelitian saat ini mengajukan 3 hipotesis yaitu: (1) ada pengaruh Self-awareness terhadap kepuasan hidup, (2) ada pengaruh ego support terhadap kepuasan hidup; dan (3) ada pengaruh self-awareness dan ego eupport terhadap kepuasan hidup.

\section{METODE PENELITIAN}

\section{Subjek}

Subjek adalah remaja akhir usia 18-21 tahun, jumlah subjek sebanyak 223 orang remaja yang terdiri dari 185 perempuan ( $17 \%$ ) dan 38 laki-laki (83. \%). Mereka terdiri dari suku jawa (38 orang $=$ $17 \%$ ), Tionghoa (121 orang = $54,3 \%$ ) dan Batak (17 orang = 7,6 \% ), serta suku bangsa lainnya $(21,1 \%)$.

\section{Teknik pengambilan data}

Teknik pengambilan data dengan menggunakan kuosioner yaitu kuosioner self-awareness, ego support dan kepuasan hidup. Kuosioner self-awareness dikembangkan dari konsep Goleman (1999) yang terdiri dari 6 item, contoh: saya tahu kapan saya marah. Reliabilitas selfawareness (chronbach alpha = 0,598). Kuosioner ego support dikembangkan dari konsep (Santrock, 2007) dan terdiri dari 6 
item, contoh: saya merasakan ada sumber pertolongan yang berharga dari teman yang peduli terhadap hidup saya. Reliabilitas ego support (chronbach alpha = .777).

Kuosioner kepuasan hidup dikembangkan dari konsep Schimack, Diener, Oishi \& Shush (2006, dalam Eid \& Larsen, 2008) menyebutkan 6 dimensi di antaranya: romantic, finances, grades, social life, recreation, dan housing. Jumlah item 27 butir. Contoh item: secara umum, saya cukup merasa puas dengan perjalanan wisata yang dapat menyegarkan pikiran saya. Adapun reliabilitas dimensi house (chronbach alpha $=0,745$ ), romantic (chronbach alpha $=$ 0,727), recreation (chronbach alpha $=0,721)$, social life (chronbach alpha $=0,747)$, finance (chronbach alpha = 0,726), grade ( chronbach alpha $=$ $0,754)$.

\section{Analisis Data}

Adapun analisis data dilakukan dengan menggunakan korelasi dan regresi. Analisis korelasi untuk mengetahui hubungan antara variabel selfawareness, ego support dengan kepuasan hidup. Analisis regresi digunakan untuk menguji hipotesis penelitian yaitu peran self-awareness dan ego support terhadap kepuasan hidup. Analisis data dengan menggunakan program SPSS versi 15.

\section{HASIL}

\section{Syarat Uji Regressi Ganda}

Ada beberapa syarat uji yang harus dilakukan sebelum analisis regresi ganda terhadap data penelitian. Semuanya terpenuhi dengan baik. Tidak terjadi multikolinieritas yaitu nilai toleransi $0,974>0,01$ dan nilai VIF $1.026<10$. Distribusi data tergolong normal, karena data tersebar di sekeling garis gambar P-P plot. Selain itu, tidak terjadinya heteroskedastisitas 
karena titik-titik scaterplots hubungan antara ego support menyebar secara acak tanpa ada pola tertentu (Nisfianoor, 2013).

\section{Hasil Uji Data}

Uji data dengan dengan kepuasan hidup $(r=0,488$, $\mathrm{p}=0,000<0,01)$, tidak ada hubungan antaara ego support menggunakan teknik korelasi dengan self-awareness ( $\mathrm{r}=0,160$, antara variable satu dengan variable yang lain. Hasil uji korelasi diketahui bahwa ada $\mathrm{p}=0,08>0,01)$, dan hubungan antara self-awareness dengan kepuasan hidup $(\mathrm{r}=.227, \mathrm{p}=$ $0,000<0,01)($ Tabel 1).

pengaruh self-awareness terhadap

Tabel 1. Hasil Uji Korelasi

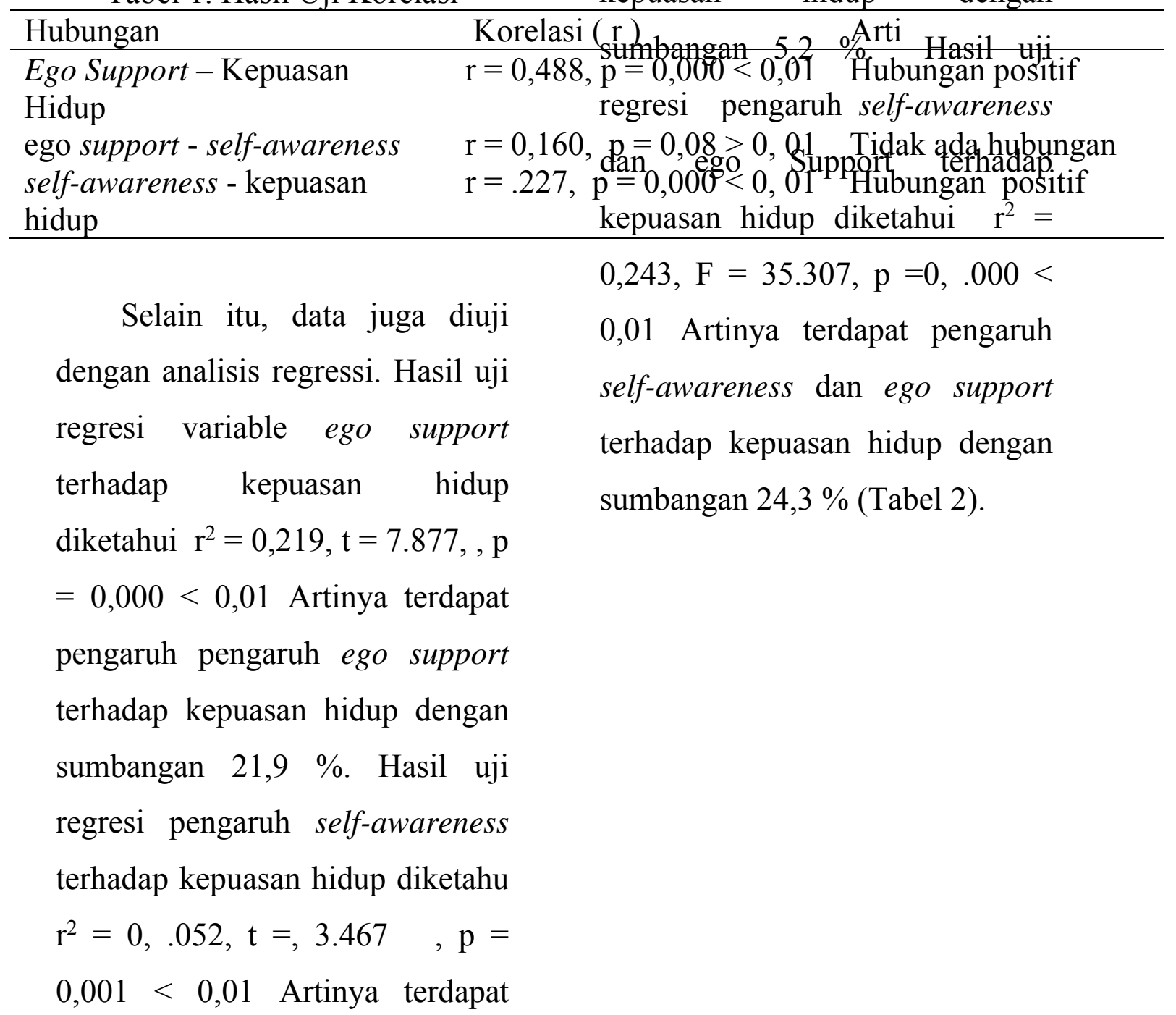


Tabel 2. Hasil Uji Regresi

\begin{tabular}{|c|c|c|}
\hline $\begin{array}{l}\text { Peran variabel thd kepuasan } \\
\text { hidup }\end{array}$ & Hasil & Sumbangan \\
\hline Ego Support - Kepuasan Hidup & $\begin{array}{l}\mathrm{r}^{2}=0,219, \mathrm{t}=7.877, \mathrm{p}=0,000< \\
0,01\end{array}$ & $\begin{array}{l}21,9 \\
\text { persen }\end{array}$ \\
\hline Self-awareness - kepuasan hidup & $\begin{array}{l}\mathrm{r}^{2}=0,052, \mathrm{t}=, 3.467 \quad, \mathrm{p}=0,001< \\
0,01\end{array}$ & 5,2 persen \\
\hline $\begin{array}{l}\text { Ego support dan self-awareness } \\
\text { terhadap kepuasan hidup }\end{array}$ & $\begin{array}{l}\mathrm{r}^{2}=0,243, \mathrm{~F}=35.307, \mathrm{p}=0, .000< \\
0,01\end{array}$ & $\begin{array}{l}24,3 \\
\text { persen }\end{array}$ \\
\hline
\end{tabular}

\section{DISKUSI}

Dalam diskusi ini akan dikemukakan mengenai ego support dan kepuasan hidup, Ego Support dan Self-Awareness, Selfawareness dan Kepuasan Hidup serta Self-awareness dan Ego Support terhadap Kepuasan Hidup.

\section{Ego Support dan Kepuasan}

\section{Hidup}

Hasil analisis uji korelasi diketahui bahwa ada hubungan yang signifikan antara ego support dengan kepuasan hidup ( $\mathrm{r}$ $=0,488, \mathrm{p}=0,000<0,01)$, artinya ego support memiliki hubungan yang erat dengan kepuasan hidup remaja. Remaja sebagai individu yang berada dalam masa peralihan benar-benar merasakan perlunya dukungan secara emosional dari lingkungan sosial. Ego support (dukungan ego) merupakan dukungan emosional yang menyentuh aspek afeksi, atau perasaan dalam diri seseorang. Dukungan emosional sebagai bentuk perhatian, kasih-sayang maupun relasi sosial dari orang lain terhadap individu tertentu.

Dengan adanya dukungan emosional, seorang remaja akan merasa diri sebagai orang yang dihargai dan diterima oleh lingkungan sosial. Lingkungan sosial bisa berasal dari keluarga, teman-teman sebaya, atau guruguru di sekolah mau bersikap peduli terhadap diri individu. Bentuk perhatian dan kepedulian tersebut akan membuat diri 
individu merasa puas atas dirinya, sehingga ia mencapai kepuasan hidup. Melalui uji analisis regresi diketahui bahwa ada pengaruh ego support terhadap kepuasan hidup $\left(r^{2}=0,219, \mathrm{t}=7.877, \mathrm{p}=\right.$ $0,000<0,01)$, artinya terdapat pengaruh ego support terhadap kepuasan hidup dengan memberikan sumbangan sebesar 21,9 \%. Masih ada sebanyak 78,1 persen yang mempengaruhi kepuasan hidup remaja.

\section{Self-awareness dan Kepuasan Hidup}

Hasil uji korelasi diketahui bahawa ada hubungan positif yang cukup signifikan antara selfawareness dengan kepuasan hidup $(\mathrm{r}=.227, \quad \mathrm{p}=0,000<0,01)$. Artinya remaja yang memiliki self-awareness yang tinggi, maka ia juga memiliki kepuasan hidup yang tinggi pula. Sebaliknya bila remaja mempunyai selfawareness rendah, maka ia juga mempunyai kepuasan hidup yang rendah. Namun ketika melihat hasil uji regresi self-awareness terhadap kepuasan hidup diketahui bahwa $\mathrm{r}^{2}=0, .052, \mathrm{t}=$, $3.467, \mathrm{p}=0,001<0,01$. Artinya pengaruh self-awareness terhadap kepuasan hidup hanya memberikan sumbangan sebesar $5,2 \%$. Dengan demikian, sumbangan self-awareness tergolong relatif kecil terhadap kepuasan hidup. Masih ada faktorfaktor lain sebanyak 94,8 \% yang mempengaruhi kepuasan hidup remaja. Mereka yang mampu menyadari diri sendiri, adalah mereka yang mampu menilai, mengevaluasi dan menerima diri sendiri apa adanya (Brill, 2000; Duval \& Silvia, 2002). Mereka akan dapat menemukan kebermaknaan dalam hidupnya (Heintzelman and King, 2014), akhirnya mereka merasa puas terhadap kehidupannya.

Self-awareness senantiasa dimiliki individu yang terbiasa untuk melakukan refleksi diri (self-reflection), suatu aktifitas yang menilai dan mengevaluasi seluruh pengalaman hidupnya 
(Andrén. 2012). Ia menyadari akan berbagai aspek pengalaman hidup yang positif maupun negatif (Duval \& Silvia, 2002). Berbagai pengalaman tersebut menjadi sumber pembelajaran yang berharga bagi dirinya (Heintzelman and King, 2014). Ia dapat memperbaiki hal-hal yang negatif dan memperteguh pengalaman yang positif, sehingga ia semakin mampu mengendalikan diri. Kemampuan mengendalikan diri menjadi kunci penting untuk dapat menghayati dan menghargai kehidupannya, sehingga ia bisa mencapai kepuasan dalam hidupnya (Yamawaki, Nelson1 and Omori, 2010).

Remaja didorong oleh kebutuhan-kebutuhan fisiologis yang bertujuan untuk mencapai kepuasan hidup. Mereka berpikir, bersikap dan bertindak untuk memenuhi aspek-aspek kebutuhan seperti romantic, finances, grades, social life, recreation, dan housing (Schimack, et al, 2006, dalam Eid \& Larsen, 2008). Sesuai dengan tahap dan tugas perkembangan remaja yang berusaha untuk mengembangkan seluruh potensinya, maka mereka menjalani relasi sosial dengan orang lain, seperti persahabatan atau berpacaran.

Masa pacaran merupakan masa yang seringkali dijalani oleh remaja. Remaja sudah mulai tertarik terhadap lawan jenis (Steinberg, 2011). Remaja wanita akan bergaul dengan laki-laki, sebaliknya remaja laki-laki bergaul dengan wanita (Santrock, 2007; Steinberg, 2011). Ketertarikan secara fisik, seperti warna kulit, wajah, tinggi badan, atau kesamaan hobi dapat menjadi pemicu remaja untuk mengembangkan suatu persahabatan (Kail \& Cavanaugh, 2010). Namun hubungan persahabatan dapat ditingkatkan statusnya lebih erat lagi menjadi hubungan pacaran. Mereka yang berhasil memiiki pacar, seringkali merasa bangga dan bahagia, atau 
mencapai kepuasan dalam hidupnya.

Secara finansial remaja masih bergantung pada orangtua. Mereka juga berusaha dapat memiliki kepuasan finansial dengan cara mendapatkan uang saku dari orangtua. Namun, mereka juga bisa belajar mandiri dengan cara bekerja agar mendapatkan uang demi mencukupi kebutuhan hidupnya. Keuangan menjadi penting bagi penunjang kehidupan remaja, karena mereka dapat menjalankan aktivitas dengan baik, jika ditopang secara finansial. Sebaliknya, mereka mengalami hambatan dalam

Dalam menempuh pendidikan akademis, remaja dituntut oleh orangtua atau gurugurunya untuk memperoleh prestasi akademik terbaik (grade). Tuntutan orangtua merupakan dukungan nyata bagi keberhasilan mencapai prestasi akademik (Wibowo \& Susanto, 2014). Keberhasilan mencapai nilai terbaik membuat mereka merasa percaya diri, optimis dan yakin akan masa depan hidupnya. Merasa merasa berharga, bangga dan puas dalam hidupnya (Dowler, et al, 2015). Sebaliknya, mereka yang gagal secara akademis di sekolah, maka mereka merasa pesimis dan kurang yakin terhadap kemampuan diri-sendiri. Bahkan mereka mengalami drop out (DO) (Janozs, Blanc, Boulerice, \& Tremblay, 2000). Mereka menjadi murung, minder, dan sulit dalam pergaulan sosial. Dengan demikian, mereka kurang puas dalam hidupnya.

Social life ialah kehidupan social seorang individu dalam lingkungan keluarga, maupun teman sebaya (Rice \& Dolgin, 2008). Lingkungan keluarga maupun teman sebaya memberikan kesempatan individu untuk mengenai mengembangkan ketrampilan bersosialisasi (social skill). Ketrampilan bersosialisasi menjadi dasar untuk 
menyesuaikan diri dalam lingkungan sosial. keberhasilan seseorang dalam menjalani kehidupan sosial akan memberi dampak terhadap kepuasan hidupnya.

Recreation ialah aktivitas menyenangkan untuk mengisi waktu luang atau senggang demi melepasan kepenatan, kebosanan atau kejenuhan hidup (Rice \& Dolgin, 2008). Kegiatan rekreasi dengan cara berwisata di alam terbuka atau mengadakan perjalanan jauh dari keramaian kota. Dengan berwisata, maka seseorang dapat merasakan kesegaran dan dapat menjalankan aktivitas kembali dengan baik (Papalia, Olds \& Feldman, 2009). Housing ialah kegiatan bersama dengan seluruh anggota keluarga di rumah, seperti orangtua, saudara-saudara kandung (sibling), atau sanak keluarga yang lain. Kegiatan ini misalnya menonton TV, film atau berkebun di halaman rumah.
Self-awareness dan Ego Support terhadap Kepuasan Hidup

Hasil uji regresi diketahui $\mathrm{r}^{2}=0, .243, \mathrm{~F}=35.307, \mathrm{p}=0, .000$ $<0,01$ Artinya secara bersamasama terdapat pengaruh selfawareness dan ego support terhadap kepuasan hidup dengan sumbangan $24,3 \%$. Kedua variabel memiliki peran yang cukup signifikan terhadap kepuasan hidup remaja. Dalam masa pertumbuhannya menuju ke masa dewasa, remaja dituntut untuk mengembangkan memahami diri sendiri (selfawareness) (Duval \& Silvia, 2002). Kesadaran diri sendiri dapat membuat hidupnya semakin mampu untuk menerima keadaan diri-sendiri apa adanya (Brill, 2000; Laurent Auzoult and Sandrine Hardy-Massard). Selain itu, seorang remaja tetap memerlukan dukungan emosional dari orang lain. Karena remaja adalah bagian dari lingkungan sosial, sehingga ia tetap menjaga relasi dengan orang lain (Aboud, 
Mendelson, \& Purdy, 2003). Dengan kedua variabel tersebut, remaja semakin mampu mengembangkan diri untuk mencapai kepuasan hidupnya.

Dalam penelitian ini, ditemukan bahwa tidak ada hubungan antaara ego support dengan self-awareness $(\mathrm{r}=0,160$, $\mathrm{p}=0,08>0,01)$. Dukungan emosional tidak memiliki hubungan dengan self-awareness. Kedua variabel ini merupakan variabel independen (mandiri) yang tidak saling berhubungan. Namun apabila keduanya digabung menjadi satu, maka keduanya mempunyai pengaruh terhadap kepuasan hidup remaja. Seorang remaja yang memiliki kesadaran diri yang positif, serta ditopang dengan dukungan emosional dari lingkungan sosial, maka ia merasakan penerimaan yang membuatnya menjadi pribadi yang berharga (Brill, 2000), dan memiliki makna hidup (Heintzelman \& King, 2014). Karena hidupnya menjadi pribadi penting, atau berguna (bermanfaat) bagi lingkungan sosial, maka ia pun merasakan adanya kepuasan dalam hidupnya (Goetzmann et al, 2014).

Dalam penelitian ini ditemukan ada perbedaan antara remaja laki-laki dan wanita dalam memandang kepuasan hidup. Remaja wanita lebih merasa puas dalam kehidupannya, dibandingkan dengan remaja lakilaki. Sesuai dengan pandangan Lamanna \& Riedmann (2012) terdapat perbedaan jender dalam konteks sosialisasi di masyarakat. Remaja wanita lebih merasa peka dalam memahami, dan menghayati kehidupannya. Remaja wanita menekankan aspek afeksi yang berkaitan dengan relasi sosial, seperti keluarga, pertemanan atau hubungan dengan teman sebaya. Sejalan dengan penemuan Patnani (2012) bahwa keluarga sebagai sumber kebahagiaan bagi wanita. Orangtua dapat mencurahkan perhatian, kasih-sayang dan 
kebutuhan afeksi bagi anakanaknya, termasuk anak wanita.

\section{SIMPULAN,}

\section{KETERBATASAN dan}

SARAN

Hasil penelitian dapat disimpulkan bahwa ada pengaruh self-awareness terhadap kepuasan hidup, ada pengaruh ego support terhadap kepuasan hidup, dan secara bersamai-sama ada pengaruh self-awareness dan ego support terhadap kepuasan hidup.

Penelitian ini menggunakan setting pada kelompok remaja yang mayoritas bersuku bangsa tionghoa. Untuk mendapatkan perbandingan dengan kelompok suku lainya, maka diperlukan penambahan jumlah subjek yang berbeda suku bangsa lain seperti Jawa atau Batak. Disarankan penelitian selanjutnya dapat melibatkan kedua suku bangsa tersebut, agar dapat dilihat perbedaan kepuasan hidup dari beragam suku-suku bangsa tersebut.
Selain itu, penyusunan konsep-konsep variabel masih mengacu pada teori-teori Barat, terutama Amerika Serikat. Karena itu, pandangan kepuasan hidup mencerminkan latar-belakang budaya Amerika Serikat dan hal ini belum tentu sesuai dengan konteks budaya Indonesia. Di masa depan, disarankan untuk membuat alat ukur Kepuasan Hidup Remaja yang sesuai dengan konteks budaya masyarakat Indonesia.

\section{DAFTAR PUSTAKA}

Aboud, F.E., Mendelson, M.J., \& Purdy, K.T. (2003). Cross-race peer relations and Friendship quality. International Journal of Behavioral

Development, 2 (7), 165 175.

Adebayo, S. O \& Arogundade, $O$ $B$ (2011). The Predictive Influence of Extraversion and Neuroticism on Life Satisfaction Judgments of Adults in Ado -Ekiti, Nigeria. British Journal of Arts and Social Sciences.3 (1), 38-49.

Andrén. U (2012). Self-awareness and self-knowledge in professions: Something 
we are or a skill we learn. Göteborg, Sweden: University of Gothernburg.

Auzoult ,L and Hardy-Massard, S (2014).

Desirability Associated with the Expression of SelfConsciousness in a French Population. Swiss Journal of Psychology, 73 (3), 183-188.

Boyd, D \& Bee, H. (2012). The Developing Child. Boston: Pearson.

Brill, R.R. (2000). Emotional Honesty and SelfAcceptance. USA: XLibris Corporation.

Comptom, W.C. (2005). An Introduction to Positive Psychology. Australia: Thomson wadsworth.

Cillessen, A. H.N., Jiang, X.L., West, T.V., \& Laszkowski, D.K (2005). Predictor of dyadic friendship quality in adolescence. International Journal of Behavioral

Development, 2 (29), 165-172.

Dariyo, A. (2015). Persahabatan, Kecerdasan Emosi dan Kepuasan Hidup Remaja. (Laporan Penelitian, Tidak Diterbitkan). Jakarta: Lembaga Penelitian dan Publikasi Ilmiah Universitas Tarumanagara.
Diener, E. (2005). Guidelines for National Indicators of Subjective Well Being and Ill Being. Illinois, USA: University of Illinois.

Diener, E., Oishi \& Lucas, (2015). National Accounts of Subjective Well-Being. American Psychologist, 70, (3), 234-242.

Diponegoro, A, M. (2004). Analisis Faktor Kepuasan Hidup Remaja. Phronesis, Jurnal Ilmiah Psikologi Terapan, 6 (12), 121133.

Dowler, C. A., Hinkle, V.A., Gibson, N., Hinkle, K. T., Wiley, E and Fiester, H. R. (2015). A Predictive Model for Student Success on the Georgia High School Science Graduation Test. International Interdisciplinary Journal of Scientific Research, 2 (1), 41-59.

Duval, T. S \& Silvia, P. J. (2002) Self-Awareness, Probability of Improvement, and the Self-Serving Bias. Journal of Personality and Social Psychology, 82, ( 1), $49-61$.

Eid, M \& Larsen, R.J. ( 2008). The Science of Subjective Well-Being. New York: The Guilford Press. 
Fridayanti. (2013). Pemaknaan Hidup (meaning in life) dalam kajian Psikologi. Psikologika, 18 (2), 189198.

Goetzmann, L., Scholz, U, Dux, R, Roellin, M, Boehler, A, Muellhaupt, Noll, B, G, Wüthrich, R. P., and Klaghofer, R (2012). Life Satisfaction and Burnout Among Heart, Lung, Liver, and Kidney Transplant Patients and Their Spouses. Swiss Journal of Psychology, 71 (3), 125-134.

Heintzelman, S.J \& King, L.A. (2014). Life Is Pretty Meaningful. American Psychologist, 69 (6), 561-574.

Janozs, M., Blanc, M.L., Boulerice, B., \& Tremblay, R.E. (2000). Predicting Different Types of School Dropouts: A Typological Approach With Longitudinal Samples. Journal of Educational Psychology, 92 (1), 171190.

Kasimatis, M. D. \& Guastello, D. D. (2012). Parenting Style Trumps Work Role in Life Satisfaction of Midlife Women. Journal of Articles in Support of the Null Hypothesis, 9 (1), 51-59. Kail, R.V \& Cavanaugh, J. C (2010).
Development: A Life Span View. Australia: Wadworth Cengage Learning.

Kumalasari, F \& Ahyani, L.N. (2012). Hubungan Antara Dukungan Sosial Dengan Penyesuaian Diri Remaja Di Panti Asuhan. Jurnal Psikologi Pitutur, 1 (1), 21-31.

Lamanna, M.A \& Riedmann, A. (2012).

Marriages, Families and Relationship. Australia: Wadworth Cengage Learning.

Lyons, M. D. Otis, K. L. Huebner, E. S, and Hills, K. J. (2014), Life Satisfaction and Maladaptive Behaviors in Early Adolescents. School Psychology Quarterly, 29 ( 4), 553-566.

Masriah, A., Putri, M.A., \& Radiaswati, D.R.A. (2012). Perbedaan Harga diri dan Subjektif Well Being antara Remaja dengan Orangtua Lengkap dan Bercerai. Jurnal Mind Set, 4 (1), 65-69.

Nisfianoor, M. (2013). Pendekatan Statistik Modern. Jakarta: Universitas Trisakti Press.

Papalia, D.E., Olds, S.W, \& Feldman, R.D. (2009). Human Development 
(11 ${ }^{\text {th }}$ edition).

Boston:McGraw-Hill.

Patnani, M. (2012). Keabahagiaan Pada Perempuan. Jurnal Psikogenesis, 1 (1), 5664.

Rice, F.P \& Dolgin, K.G. (2008).

Adolescence:

Development,

Relationship and

Culture. (12 ${ }^{\text {th }}$ edition).

Boston: Pearson

Education.

Santrock, J.W. (2007).

Adolescence. Boston:

McGraw-Hill.

Schimmack, U (2009). Well-

Being: Measuring Well-

Being in the SOEP. Berlin: Duncker \& Humblot, Smollers Jarbuch, 129, 1-9.

Steinberg,

L.

(2011).

Adolescence. $\quad\left(9^{\text {th }}\right.$

edition). Boston:

McGraw-Hill.

Thomasson, A.L. (2006). Self awareness and Self Knowlwedge. Psyche, 2 (16), 1-15.

Wibowo, M. W \& Susanto, D.Y (2014).

Dinamika

Dukungan Sosial pada

Prestasi Siswa Sekolah

Dasar: Suatu Pendekatan

Indigenous Psychology.

Jurnal

Psikologi

Tabularasa, 9 (1), 24-29.

Yamawaki, N, Nelson, J. A. P and Omori, M., (2010).

Self-esteem and life satisfaction as mediators between parental bonding and psychological wellbeing in Japanese young adults. International Journal of Psychology and Counselling. 3 (1), 18 . 